\section{AVALIAÇÃO AUDITIVA DE SEQUÊNCIAS \\ SONƠRO-MUSICAIS: UM ESTUDO \\ PILOTO PARA VALIDAÇÃO DE TESTE MUSICAL PARA PESSOAS COM TRANSTORNO DO ESPECTRO AUTISTA ${ }^{1}$}

\section{Viviane Louro, Liliane Desgualdo, Fabiana Louro,} Maria José da Silva Fernandes ${ }^{2}$

RESUMO: Este estudo tem como objetivo apresentar dados preliminares sobre a elaboração e aplicação de um teste musical para avaliaçáo da aprendizagem musical em crianças e adolescentes com Transtorno do Espectro Autista (TEA). $\mathrm{O}$ teste, batizado como "Avaliação Auditiva de Sequências Sonoro-Musicais", tem suas bases teóricas nas habilidades neurológicas do processamento auditivo e nas etapas do desenvolvimento propostas por Wallon, em diálogo com os conteúdos geralmente abordados dentro de um processo de iniciação musical. $\mathrm{O}$ piloto mostrou que o teste possui aplicabilidade em indivíduos com e sem deficiências, ambos musicalizados. $\mathrm{O}$ teste será aplicado a pessoas com autismo, e após 6 meses de aula de música, esses serão reavaliados por meio de testes cognitivos, auditivos e neuroquímicos, além do teste musical. Será feita uma correlação dos dados comportamentais com a concentraçáo de serotonina e BDNF no plasma.

PALAVRAS-CHAVE: Educação musical; Cognição; BDNF, Serotonina, Transtorno do espectro autista.

HEARING ASSESSMENT OF SOUND-MUSICAL SEQUENCES: A PILOT STUDY TO VALIDATE A MUSICAL TEST FOR PEOPLE WITH AUTISM SPECTRUM DISORDERS

ABSTRACT: The aim of this study is to present preliminary data on the development and implementation of a musical test for evaluating the musical learning in children and adolescents with Autism Spectrum Disorder (ASD). The test,
1. As autoras agradecem o apoio financeiro concedido pelo CNPq, CAPES, FAPESP e FAP.

2. Departamento de Neurologia e Neurocirurgia/ Departamento de Fonoaudiologia Universidade Federal de São Paulo (UNIFESP). Email:vviviane_louro@uol. com.br. 
named "Hearing Assessment of Sound-Musical Sequences", has its theoretical basis in neurological auditory processing skills and the stages of development proposed by Wallon, in dialogue with the contents usually addressed within a musical initiation process. The results of the pilot testing indicated that it has applicability in individuals with and without disabilities, both with musical initiation. The test will be applied to people with autism, and after 6 months of music lessons, these will be reassessed by cognitive, auditory and neurochemical tests, as well as a musical test. A correlational study will be performed between the behavioral data and the concentration of serotonin and BDNF in plasma.

KEYWORDS: Music education; Cognition; BDNF; Serotonin; Autism spectrum disorder;

3. O Transtorno do Espectro Autista (TEA), termo atualmente utilizado, abrange um grupo de condiçóes que afeta aproximadamente 1 em cada 200 indivíduos, sendo a maior parte, meninos. As principais características são: graves dificuldades nas habilidades sociais e comunicativas; dificuldade de imaginação; movimentos repetitivos (chamados de estereotipias); interesses a assuntos específicos (presente em alguns somente) (KLIN, 2006);.É dividido em grau leve, moderado e grave (APA,

2013).

4. Disponível em <www. sonustech.com/pavacini/>. Acesso em 20 de Outubro de 2013.

5. Falas repetitivas empregadas sem contexto, também chamada de estereotipia vocal ou da fala (APA, 1994).

\section{INTRODUÇÃO I. MÚSICA E TRANSTORNO DO ESPECTRO AUTISTA (TEA)}

Em pessoas com $\mathrm{TEA}^{3}$, não é raro a existência de habilidades específicas, por vezes surpreendentes, sendo o potencial musical uma dessas habilidades presentes em muitos casos. Só para citar um exemplo, temos Derek Pavacini ${ }^{4}$, que além de autista é cego, e é atualmente um dos grandes expoentes da música popular e erudita nos Estados Unidos da América (EUA).

A música é de grande utilidade para crianças com TEA, pois as ajuda a serem mais espontâneas quanto à comunicação, diminuindo o isolamento e a ecolalia ${ }^{5}$ (PADILHA, 2008). Além disso, a música colabora na diminuição das dificuldades sensoriais e na integração social quando é utilizada em atividades em grupos (MILLER e ELLER-MILLER, 1989) e devido sua propriedade não-verbal, é uma ferramenta eficaz para o desenvolvimento da linguagem (WIGRAM e GOLD, 2006).

Mesmo a música sendo uma via de comunicação para muitos autistas e utilizada terapeuticamente de forma enfática e sistemática com esse público, pouco se explorou cientificamente sobre os benefícios que a aprendizagem musical pode oferecer no desenvolvimento global dessas pessoas. Dentre 
as pesquisas na área, podemos recortar: Barros (2010) que relatou um caso de intervenção musical em uma criança autista; Wigram (2006), Padilha (2008) e Kafies et al. (2008) que realizaram trabalhos empregando a música em grupos de autistas; Mottron et al. (2000) que pesquisou as habilidades auditivas musicais de um grupo de autistas e náo autistas; Lai (2012) que mapeou diferenças neurológicas entre a percepção da fala e dos sons em crianças com autismo. A grande maioria dessas pesquisas teve enfoque terapêutico ou então, abordaram a música do ponto de vista da acuidade auditiva, tentando mapear regióes neurológicas referentes à percepçáo que esses indivíduos tinham dos sons.

Um estudo com o objetivo de aplicar a educação musical como método de intervenção em pessoas com autismo encontra-se em andamento na Disciplina de Neurologia Experimental do Departamento de Neurologia e Neurocirurgia da Universidade Federal de São Paulo. Esse estudo pretende avaliar o impacto da educação musical em parâmetros neurofisiológicos, comportamentais (interação social), cogniti$\operatorname{vos}^{6}$, fonoaudiológicos (processamento auditivo e linguagem) e musicais (aprendizagem musical) de pacientes com TEA. Os pacientes deverão frequentar no mínimo quatro meses de aulas de música preparadas com base nas atividades convencionais da educação musical.

A metodologia empregada será baseada principalmente nas propostas de Dalcroze (parte rítmica-motora) unidas aos princípios da psicomotricidade (bateria psicomotora do Vitor da Fonseca) e à fundamentação teórica da Teoria da Mente (FONSECA, 2007, 2008, 2012; MATEIRO, 2011).

Os testes serão aplicados em 24 pessoas com TEA grau leve de 5 a 16 anos de idade, selecionadas por neurologista de acordo com as características traçadas pelo DSM-V (APA, 2013). Essas pessoas serão divididas em dois grupos: o primeiro formado por 12 pessoas que terão aulas de música duas vezes por semana, com uma hora e vinte minutos de duração cada e o outro, também formado por 12 pessoas, que farão os testes iniciais e finais, mas não serão submetidos às aulas de música (grupo controle). As aulas serão realizadas na APAE de São Paulo em parceira com a UNIFESP ${ }^{7}$.
6. Está sendo usado o conceito cognição baseado em Fonseca (2007, pg. 31): “processos e produtos mentais superiores (conhecimento, consciência, pensamento, imaginação, criatividade, produção de planos e estratégias, resolução de problemas, inferência, conceitualização e simbolização), através dos quais percebemos, concebemos e transformamos o envolvimento."

7. Todo material da pesquisa (equipamentos; papelaria; jogos pedagógicos e instrumentos musicais) foram subsidiados pelo Fundo de Amparo à Pesquisa (FAP). 
Alguns parâmetros serão avaliados antes e após quatro meses de aplicaçáo do protocolo de música, conforme detalharemos a seguir.

2. TESTES COMPORTAMENTAIS E ESTUDO NEUROQUÍMICO

Os testes a serem realizados na pesquisa são todos reconhecidos e validados cientificamente, a saber:

1. Dosagem de serotonina no sangue: A serotonina é uma monoamina que exerce um papel fundamental em processos de aprendizagem e memória e sua análise no sangue permite inferir sobre alteraçóes que possam ocorrer em áreas do cérebro.

2. Dosagem de BDNF: O BDNF (do inglês brain-derived neurotrophic factor) é uma proteína que pertence à família das neurotrofinas e é liberada em áreas relacionadas com processo de aprendizagem e memória, tais como hipocampo, córtex e prosencéfalo basal. Este fator está envolvido na memória de longa duração e na neurogênese (BEKINSCHTEIN et al., 2008).

3. Escala de Inteligência de Wechsler para Crianças e Adolescentes (WISC-III): consiste em obter uma medida geral da inteligência. $O$ teste consta de 13 subtestes divididos em avaliaçóes verbais e não verbais. Empregaremos a versão compilada, também validada, no qual são utilizados somente dois subtestes: um verbal e outro náo verbal. A escolha se deve às dificuldades comportamentais geralmente apresentadas no Transtorno do Espectro Autista (WECHSLER, 1991).

4. Teste fonoaudiológico: A avaliação da audição (audiometria) será aplicada para detectar se existe alguma alteração que possa interferir na compreensão e interpretação do som (Processamento auditivo central) (DIAS, 2005).

A escolha dos testes permitirá medir o impacto da música sobre alguns parâmetros fisiológicos, cognitivos, de linguagem e comportamentais em pacientes com TEA. Entretanto, como a ferramenta principal do trabalho em questão é a aprendizagem musical, o corpo de pesquisadores julgou necessário aplicar também uma avaliação nesse sentido. 
Uma busca detalhada sobre avaliações e testes musicais foi feita nos principais bancos de dados de pesquisas (Lilacs, Pubmed, Scielo, Medline), nas revistas de educação musical da Associação Brasileira de Educação Musical (ABEM), na revista Revista Brasileira de Musicoterapia e nos bancos de dados das bibliotecas das faculdades de música do Brasil. Não foi encontrada nenhuma avaliação, instrumento de medida ou teste que tenha sido estudado com o mesmo enfoque do presente estudo justificando a necessidade da criação de um teste para a pesquisa. Isso confirma as palavras de Silva (2012) que comenta sobre a escassez de instrumentos de avaliação musical, validados no Brasil.

Silva (2012) traduziu para o português do Brasil uma escala americana de medida em musicoterapia e Pacheco (2009) propôs um teste para perceber as habilidades musicais e consciência fonológica de crianças de quatro e cinco anos de idade, mas nenhum deles propôs um método que pudesse mensurar os benefícios da música em crianças e adolescentes com autismo. Mais uma justificativa para a nossa proposição ${ }^{8}$.

\section{O TESTE DE MÚSICA - FUNDAMENTAÇÃO TEÓRICA}

O teste musical foi fundamentado sobre três pilares: 1. As etapas do desenvolvimento propostas por Wallon para as idades acima de cinco anos; 2. As habilidades neurológicas do processamento auditivo a partir de cinco anos de idade; 3 . Os conteúdos musicais básicos utilizados na iniciaçáo musical.

\section{$1^{\circ}$ pilar: etapas do desenvolvimento de Wallon}

Em Wallon é impossível dissociar a ação da representação, a tonicidade da emoção, o gesto da palavra, o motor do psiquismo. Não há separação possível entre indivíduo e meio ambiente (FONSECA 2008). Cada fase é um sistema de relaçóes entre as capacidades da criança e do meio que faz com que eles se especifiquem reciprocamente (WALLON, 2007).

A escolha de Wallon, como parte do embasamento teórico para a elaboração do teste, se deu, devido à aproximação de sua visão de desenvolvimento, brevemente comentada anteriormente, com o que propóe um trabalho pedagógico musical bem fundamentado. Isso é parte de um fazer musical
8. Cabe ressaltar que os resultados apresentados nesse manuscrito se referem a um estudo piloto. 
global, com base numa proposta significativa, que dialogue com o contexto sociocultural trazido pelo aluno, sem deixar de considerar obviamente, os estágios neurológicos através dos aspectos cognitivos, afetivos e maturação motora do indivíduo. Tudo isso deve estar em consonância com os conteúdos musicais propostos pelo educador, sejam eles quais forem (LOURO, 2012).

Resumidamente, as etapas de Wallon são (FILHO, 2009):

Sensório-motor e projetivo (de 1 a 3 anos): caracteriza-se pela exploraçáo concreta do espaço físico pelo agarrar, segurar, manipular, apontar, sentar, andar, etc., acompanhadas e auxiliadas pela linguagem.

Personalismo (de 3 a 6 anos): marcado pela construçáo da subjetividade por meio das atividades de oposiçáo e, ao mesmo tempo, de imitaçáo. A passagem do ato motor ao ato mental opera-se por meio da percepçáo consciente do corpo, uma representação vivida experiencialmente e integrada contextualmente. As distâncias espaciais começam ser relativizadas frente ao seu próprio corpo esquematizado e imaginado e o meio começa a modificar-se frente aos desejos, motivaçóes internas e interesses. $\mathrm{O}$ espaço se torna em algo real ao alcance da fantasia e passa a ser navegado por uma dimensão passível de representação gráfica.

Categorial (de 6 a 11 anos): existe a predominância do conjunto cognitivo. Nesse momento a criança consegue, pelas atividades do pensamento, organizar o mundo em categorias mais definidas que, por sua vez, permitem uma melhor compreensão dela mesma. Neste estágio a criança torna-se mais atenta e autodisciplinada, mais inibida em termos motores e mais concentrada em termos sensoriais. Melhora a planificação motora.

Puberdade e adolescência (acima de 11 anos): há ganhos na forma de pensar (pelo desenvolvimento do raciocínio hipotético-dedutivo) e uma maior exploração de si mesmo como identidade autônoma, mediante atividades de confronto e autoafirmação e, paralelamente, pela busca de apoio no grupo de mesma idade. Este período subentende uma profunda reorganização do esquema corporal, um profundo mergulho dentro de si, o que poderá originar ambivalências múltiplas nas atitudes, nos sentimentos e nas necessidades. 
O teste de música elaborado para a pesquisa se baseou principalmente no que Wallon coloca como habilidades ou possibilidades cognitivas das fases Personalismo, Categorial e Puberdade, pois foi arquitetado para pessoas de 5 a 15 anos de idade.

Para sua confecção, foi levado em consideração o uso de sequências auditivas possíveis para cada idade em relação à cognição e memória, a partir de Luria (1997): dois sons para o estágio personalismo; três sons para o estágio categorial e quatro sons para o estágio puberdade.

A execução das respostas também foi elaborada pensando em cada estágio, a partir de Luria (1997), Lampreia (2008) e Fonseca (2008). Para o estágio Personalismo, optou-se somente pelo uso de fichas com desenhos ilustrativos, no qual, os alunos tem que apontar a opção correta a partir da escuta. No $2^{\circ}$ estágio, o Categorial, o uso de figuras diminui e acrescentam-se algumas atividades escritas e no último estágio, $\mathrm{Pu}$ berdade, todas as respostas são escritas.

$2^{\circ}$ e $3^{\circ}$ pilares: aspectos do processamento auditivo e conteúdos musicais

De acordo com Mendonça e Lemos (2010):

O aprendizado e o desenvolvimento musical dependem das experiências acústicas vivenciadas, incluindo a discriminação dos sons, a habilidade para perceber temas musicais, a sensibilidade para ritmos, texturas e timbre, e a habilidade para produzir e/ou reproduzir música.

O desenvolvimento das habilidades auditivas ocorre em etapas semelhantes e sucessivas para a maioria dos indivíduos e dependem tanto do aspecto biológico, relacionado à constituição anatômica, como também do aspecto maturacional, relacionado à experiência acústica de cada um (PEREIRA, 2002). Sendo assim, o segundo pilar do teste é o processamento auditivo que está diretamente em diálogo com o $3^{\circ}$ pilar: os conteúdos musicais.

O processamento auditivo diz respeito às funçóes cerebrais que interpretam e compreendem o som, tendo como representante o lobo temporal (BONALDI, 2004). Sendo assim, o teste também foi baseado nas habilidades neurológicas ine- 
rentes ao ser humano no reconhecimento e interpretaçáo do mundo sonoro ao seu redor (PEREIRA, 2011). A American Speech Language Hearing Association (ASHA 1996) classifica as habilidades do processamento auditivo e entre elas destaca três que estáo relacionadas diretamente com os conteúdos da musicalização (Tabela 1).

\begin{tabular}{|l|l|l|}
\hline $\begin{array}{l}\text { Aspecto do } \\
\text { processamento } \\
\text { auditivo }\end{array}$ & $\begin{array}{l}\text { Descrição } \\
\text { (ASHA, 1996) }\end{array}$ & $\begin{array}{l}\text { Conteúdo } \\
\text { musical }\end{array}$ \\
\hline $\begin{array}{l}\text { Discriminação } \\
\text { auditiva }\end{array}$ & $\begin{array}{l}\text { capacidade de } \\
\text { reconhecer os } \\
\text { sons verbais e não } \\
\text { verbais }\end{array}$ & Timbre \\
\hline $\begin{array}{l}\text { Reconhecimento } \\
\text { do padrão audi- } \\
\text { tivo }\end{array}$ & $\begin{array}{l}\text { capacidade de re- } \\
\text { conhecer padróes } \\
\text { de frequências, } \\
\text { duração e inten- } \\
\text { sidade }\end{array}$ & $\begin{array}{l}\text { Altura; Duraçáo e } \\
\text { Intensidade }\end{array}$ \\
\hline $\begin{array}{l}\text { Aspectos tempo- } \\
\text { rais da audição }\end{array}$ & $\begin{array}{l}\text { capacidade de se- } \\
\text { quenciar os sons, } \\
\text { de perceber "o } \\
\text { silêncio" entre os } \\
\text { sons e de perceber } \\
\text { os aspectos supra- } \\
\text { segmentais da fala }\end{array}$ & $\begin{array}{l}\text { Intenção musical; } \\
\text { andamento, sons } \\
\text { e pausas; contar } \\
\text { quantidade dos } \\
\text { sons em sequência } \\
\text { (pulso, ritmo) }\end{array}$ \\
\hline
\end{tabular}

Tabela 1. Três aspectos do processamento auditivo e sua relaçáo com as propriedades do som.

De acordo com a literatura, crianças a partir de cinco anos

9. O teste foi elaborado para a pesquisa em desenvolvimento e, nela, as aulas de música oferecidas abordarão os temas supracitados. Como

o objetivo do teste será observar se os alunos com TEA tiveram uma aprendizagem musical significativa, nada mais coerente do que estruturar a avaliaçáo baseada nos conteúdos das aulas. já conseguem distinguir timbres familiares, a pulsação, e de ordenar uma serie de três sons em sequências. A capacidade de nomear os eventos acústicos musicais associados ao movimento do pulso e ritmos, devido à maturação motora e cognitiva (SLOBODA, 2008). Por esse motivo o teste é somente auditivo, e náo exige aspectos executivos do fazer musical.

Devido à diferença entre a capacidade de percepção e memória auditiva frente às faixas etárias, o teste conta com três versóes: uma para crianças de 05 e 06 anos; outra para crianças de 07 a 10 anos e a última para acima de 11 anos. Os conteúdos musicais definidos como importantes de serem avaliados foram selecionados a partir do que Mateiro (2011) e Pacheco 
(2009) propóem como um trabalho de base num processo de iniciação musical $^{9}$ (Tabela 2), lembrando que foi feito um recorte de tais conteúdos com foco nas questóes auditivas.

\begin{tabular}{|l|l|}
\hline $\begin{array}{l}\text { Conteúdos musicais } \\
\text { avaliados }\end{array}$ & Descriçáo \\
\hline Intensidade (Volume) & $\begin{array}{l}\text { Identificaçáo auditiva de } \\
\text { sons fortes e piano }\end{array}$ \\
\hline Timbre & $\begin{array}{l}\text { Identificaçáa auditiva de } \\
\text { sons do cotidiano, natureza } \\
\text { e instrumentos musicais }\end{array}$ \\
\hline Duraçáo & $\begin{array}{l}\text { Identificaçáo auditiva de } \\
\text { sons curtos e longos }\end{array}$ \\
\hline Altura & $\begin{array}{l}\text { Identificaçáo auditiva de } \\
\text { sons agudos e graves }\end{array}$ \\
\hline Andamento & $\begin{array}{l}\text { Identificaçáa auditiva da } \\
\text { velocidade (lento-rápido) de } \\
\text { trechos musicais }\end{array}$ \\
\hline Pulso & $\begin{array}{l}\text { Identificaçáo auditiva de } \\
\text { quantidade de pulsos feitos } \\
\text { em sequência }\end{array}$ \\
\hline Apreciaçáo Musical & $\begin{array}{l}\text { Identificaçáo auditiva de } \\
\text { estilos musicais (capoeira, } \\
\text { rock, rap, baiáo, samba etc) } \\
\text { e de formaçóes musicais } \\
\text { (orquestra, fanfarra, etc) }\end{array}$ \\
\hline
\end{tabular}

Tabela 2. Conteúdos musicais a serem avaliados. Com base em Mateiro (2011) e Pacheco (2009).

Hargreaves e Zimmerman (2006) dissertaram profundamente sobre a aquisiçáo dos conceitos musicais e chegaram à conclusão de que há padróes regulares de desenvolvimento musical ligado à idade, mas esses náo integram estágios etários claros e definitivos. Pacheco (2009) propôs uma divisão hierárquica da aquisição de conteúdo e conceitos musicais com base nos estudos de Hargreaves e Zimmerman (2006), sendo ela: volume, timbre, tempo, duração, altura e harmonia. Portanto, como é difícil definir etapas precisas de organização da aquisiçáo musical por haver diversas teorias e propostas hierárquicas, as questôes do teste musical apresen- 
tados neste artigo, foram organizadas a partir da concepçáo de Pacheco (2009).

\section{A ORGANIZAÇÃO E APLICAÇÃO DO TESTE}

O teste consta de doze questóes, todas de cunho auditivo, divididas em seis categorias (cada categoria tem duas questôes); cada questão é composta por três exercícios e cada exercício é formado por sequências sonoro-musicais, sendo que a quantidade de sons de cada sequencia muda conforme a faixa etária (Tabela 3).

\begin{tabular}{|l|l|l|}
\hline Categorias & Questóes & Exercícios \\
\hline $\begin{array}{l}\text { INTENSIDADE } \\
\text { (VOLUME) }\end{array}$ & $\begin{array}{l}1 \text { - Reconhe- } \\
\text { cimento auditivo } \\
\text { de sons fortes e } \\
\text { pianos (fracos) } \\
\text { isolados }\end{array}$ & A, B e C \\
\cline { 2 - 2 } & $\begin{array}{l}\text { 2- Reconhe- } \\
\text { cimento auditivo } \\
\text { de sons fortes e } \\
\text { pianos (fracos) } \\
\text { dentro de um } \\
\text { contexto musical }\end{array}$ & A, B e C \\
\hline TIMBRE & $\begin{array}{l}\text { 3- Reconhe- } \\
\text { cimento auditivo } \\
\text { de sons produ- } \\
\text { zidos pelo corpo } \\
\text { humano; sons de } \\
\text { animais e sons } \\
\text { de fenômenos da } \\
\text { natureza }\end{array}$ & A, B e C \\
\cline { 2 - 3 } & $\begin{array}{l}\text { 4- Reconheci- } \\
\text { mento auditivo de } \\
\text { sons produzidos } \\
\text { por objetos do } \\
\text { cotidiano, meios } \\
\text { de transporte e } \\
\text { situaçós diversas }\end{array}$ & \\
\hline
\end{tabular}




\begin{tabular}{|c|c|c|}
\hline \multirow[t]{2}{*}{ TEMPO } & $\begin{array}{l}5 \text { - Reconheci- } \\
\text { mento auditivo e } \\
\text { localizaçáo espa- } \\
\text { cial de quantidade } \\
\text { de pulsos }\end{array}$ & $A, B$ e C \\
\hline & $\begin{array}{l}6 \text { - Reconheci- } \\
\text { mento auditivo de } \\
\text { velocidades de } \\
\text { trechos musicais } \\
\text { (rápido e lento) }\end{array}$ & $A, B$ e C \\
\hline \multirow[t]{2}{*}{ DURAÇÃO } & $\begin{array}{l}7 \text { - Reconhe- } \\
\text { cimento auditivo } \\
\text { de sons curtos e } \\
\text { longos }\end{array}$ & $A, B$ e C \\
\hline & $\begin{array}{l}8 \text { - Reconheci- } \\
\text { mento auditivo de } \\
\text { divisão do pulso } \\
\text { em dois e quatro } \\
\text { sons (ritmo) }\end{array}$ & $A, B$ e C \\
\hline \multirow[t]{2}{*}{ ALTURA } & $\begin{array}{l}9-\text { Reconheci- } \\
\text { mento auditivo de } \\
\text { direçáo sonora } \\
\end{array}$ & $A, B$ e C \\
\hline & $\begin{array}{l}10 \text { - Reconhe- } \\
\text { cimento auditivo } \\
\text { de sons graves e } \\
\text { agudos definidos }\end{array}$ & $A, B$ e $C$ \\
\hline \multirow[t]{2}{*}{$\begin{array}{l}\text { APRECIAÇÃO } \\
\text { MUSICAL }\end{array}$} & $\begin{array}{l}11 \text { - Reconheci- } \\
\text { mento auditivo de } \\
\text { sons de instru- } \\
\text { mentos musicais }\end{array}$ & $A, B$ e $C$ \\
\hline & $\begin{array}{l}12-\text { Reconheci- } \\
\text { mento auditivo de } \\
\text { estilos musicais } \\
\text { diversos }\end{array}$ & $A, B$ e $C$ \\
\hline
\end{tabular}

Tabela 3. Organização das questôes do teste musical. Baseado em Pacheco (2009).

O critério de pontuação para o teste foi baseado em pontuaçóes numéricas empregadas às categorias: executou plenamente; executou parcialmente; não executou (Tabela 4). Cada uma das seis categorias permitem no máximo 60 pontos e a soma total do teste é de 360 . Os pontos são anotados numa folha à parte denominada "gabarito de pontos" que permite 
o professor, além da marcar a pontuação, anotar a resposta do aluno e outras observaçóes que julgue importantes.

Cabe ressaltar, que apesar de três versóes diferentes do teste (um para cada grupo etário), as questóes são as mesmas em todos eles, o que difere é a quantidade de sequências sonoro-musicais dos exercícios e a forma de resposta dada pelo aluno (Tabela 5).

\begin{tabular}{|l|l|l|}
\hline Categoria & Descriçáo & Pontuaçáo \\
\hline $\begin{array}{l}\text { Executou perfeita- } \\
\text { mente }\end{array}$ & $\begin{array}{l}\text { Quando se execu- } \\
\text { ta corretamente o } \\
\text { exercício com até } \\
\text { três repetiçóes }\end{array}$ & 10 pontos \\
\hline $\begin{array}{l}\text { Executou parcial- } \\
\text { mente }\end{array}$ & $\begin{array}{l}\text { Quando se } \\
\text { executa parte do } \\
\text { exercício com até } \\
\text { três repetiçóes; }\end{array}$ & 5 pontos \\
\hline Não executou & $\begin{array}{l}\text { Quando não se } \\
\text { executa o exer- } \\
\text { cício após três } \\
\text { repetiçóes }\end{array}$ & 0 ponto \\
\hline
\end{tabular}

Tabela 4. Descrição e pontuação das categorias de avaliação do teste.

\begin{tabular}{|l|l|l|}
\hline Idade & $\begin{array}{l}\text { Sequências } \\
\text { sonoro-musicais }\end{array}$ & Forma de resposta \\
\hline 05 e 06 anos & 2 por exercício & $\begin{array}{l}\text { Fichas com } \\
\text { desenhos ilustra- } \\
\text { tivos; materiais } \\
\text { em EVA; materi- } \\
\text { ais em madeira; } \\
\text { cartóes com cores } \\
\text { e setas. }\end{array}$ \\
\hline 07 a 10 anos & 3 por exercício & $\begin{array}{l}\text { Fichas com desen- } \\
\text { hos ilustrativos; } \\
\text { atividades escri- } \\
\text { tas; materiais em } \\
\text { madeira; cartóes } \\
\text { com setas. }\end{array}$ \\
\hline
\end{tabular}




\begin{tabular}{|l|l|l|}
\hline 11 a 15 anos & 4 por exercício & $\begin{array}{l}\text { Fichas com } \\
\text { palavras escritas; } \\
\text { atividades escritas; } \\
\text { fichas com setas. }\end{array}$ \\
\hline
\end{tabular}

Tabela 5. Resumo das sequências sonoro-musicais e modo de respostas para cada grupo etário.

\section{OBJETIVOS E MATERIAIS DO TESTE}

O teste tem como objetivo avaliar a aprendizagem de habilidades musicais auditivas geralmente trabalhadas num processo de iniciaçáo musical. $\mathrm{O}$ estudo piloto teve como foco avaliar não somente a aprendizagem musical, mas também a aplicabilidade e a eficiência do teste, pelos seguintes parâmetros:

1. Duração da aplicação: o período de tempo levado para completar todo o teste;

2. Atenção e tolerância dos alunos: se o tempo levado para aplicação cansou ou náo os alunos; se os alunos prestaram atenção devidamente;

3. Organização das questóes e enunciados: clareza do enunciado de cada questão;

4. Gravaçốes dos CDs do teste: clareza e objetividade;

5. Adaptações: eficácia das adaptaçôes propostas para os alunos não alfabetizados;

6. Fichas e figuras: se o aluno conseguiu reconhecer e compreender as figuras contidas nas fichas de respostas (os não alfabetizados e as crianças até 6 anos);

7. Gabarito de pontos: se o gabarito de pontuação final estava coerente com a organizaçáo das questôes.

\section{Materiais a serem empregados no teste:}

- Gravação de cada grupo de faixa etária ${ }^{10}$;

- Folhas de respostas dos alunos;

- Gabaritos de pontos com anotaçóes do professor;

- Materiais complementares: fichas, figuras, materiais em EVA e em madeira.
10. Os exemplos sonoros dos exercícios, tais como, sequencia de sons fortes e fracos, de direção sonora e de alturas definidas foram gravadas em estúdio exclusivamente para o teste. Para os exemplos de trechos musicais foram utilizadas no máximo 15 segundos de gravaçóes do repertório de domínio público. 
11. Em ambos os locais, integra as aulas de música, os conteúdos analisados no teste.

12. Um aluno sem deficiência de 6 anos; 1 aluno com deficiência intelectual (20 anos) e 1 aluno com autismo $(20$ anos).

13. A adaptação dos materiais foi feita para os alunos não alfabetizados; as questóes e o tempo de realização foram os mesmos para todos.

\section{O ESTUDO PILOTO}

\section{METODOLOGIA}

O estudo piloto foi realizado com 45 estudantes de música (ambos com aulas de música há mais de seis meses), divididos em dois grupos distintos: o primeiro, com alunos sem deficiência de uma ONG que promove aulas de musicalização para crianças e adolescentes carentes na região do Imirim, em Santana, São Paulo-SP; o segundo, pessoas com deficiências que fazem aulas de música na região de Santo André, São Paulo-SP (Tabelas 6, 7 e 8) ${ }^{11}$.

Apesar de a avaliação ter sido elaborada para até 15 anos de idade, o teste foi aplicado em um grupo de adultos com deficiências por três motivos: 1 - Não foi encontrado em São Paulo um grupo de crianças e adolescentes (5-15 anos) com deficiência que fossem musicalizadas num processo pedagógico musical que abordasse os conteúdos presentes no teste; 2 - Mesmo sendo adultos, o grupo do estudo piloto possui deficiência intelectual significativa, fazendo com que as habilidades cognitivas sejam semelhantes àquelas dos alunos sem deficiência com faixas etárias entre 11 e 15 anos; 3 - O objetivo do estudo foi verificar sua eficiência e aplicabilidade para posteriormente poder ser aplicado em pessoas com TEA, conforme apresentamos anteriormente, sendo assim, julgou-se necessário aplicar o teste também num grupo de pessoas com deficiência.

A duração da aplicação em todas as turmas foi de aproximadamente uma hora. Para alunos náo alfabetizados ${ }^{12} \mathrm{o}$ teste foi realizado com respostas em forma de figuras, onde os alunos precisavam assinalar a resposta ou organizar fichas a partir da comanda auditiva ${ }^{13}$. Todas as questóes do teste foram gravadas para que todos tivessem o mesmo estímulo auditivo e cada questáo foi repetida 3 vezes com todos os alunos. 


\begin{tabular}{|l|l|l|l|}
\hline $\begin{array}{l}\text { Alunos sem } \\
\text { deficiência }\end{array}$ & Quantidade & $\begin{array}{l}\text { Alunos com } \\
\text { deficiência }\end{array}$ & $\begin{array}{l}\text { Quanti- } \\
\text { dade }\end{array}$ \\
\hline $\begin{array}{l}\text { Sexo femi- } \\
\text { nino }\end{array}$ & 16 & Sexo feminino & 2 \\
\hline $\begin{array}{l}\text { Sexo mascu- } \\
\text { lino }\end{array}$ & 17 & $\begin{array}{l}\text { Sexo mascu- } \\
\text { lino }\end{array}$ & 10 \\
\hline
\end{tabular}

Tabela 6. Número de alunos do estudo piloto - Sem deficiência - ONG de SP; Com deficiência - grupo de teatro de Santo André.

\begin{tabular}{|l|c|}
\hline Idade & Quantidade \\
\hline $05-06$ anos & 3 \\
\hline $07-10$ anos & 11 \\
\hline $11-15$ anos & 19 \\
\hline
\end{tabular}

Tabela 7. Divisão dos alunos sem deficiência pela faixa etária.

\begin{tabular}{|l|c|l|}
\hline Idade & Quantidade & Diagnóstico \\
\hline 20 anos & 3 & $\begin{array}{l}\text { Deficiência } \\
\text { Intelectual }\end{array}$ \\
\cline { 2 - 3 } & 1 & Autismo \\
\hline 25 anos & 2 & $\begin{array}{l}\text { Deficiência } \\
\text { Intelectual }\end{array}$ \\
\hline 27 anos & 1 & $\begin{array}{l}\text { Deficiência } \\
\text { Intelectual }\end{array}$ \\
\hline 28 anos & 1 & $\begin{array}{l}\text { Deficiência } \\
\text { Intelectual }\end{array}$ \\
\hline 33 anos & 1 & $\begin{array}{l}\text { Deficiência } \\
\text { Intelectual }\end{array}$ \\
\hline 35 anos & 2 & $\begin{array}{l}\text { Autismo } \\
\text { Inteliectual }\end{array}$ \\
\hline
\end{tabular}

Tabela 8. Divisão dos alunos com deficiência pela faixa etária. 
14. Nos quadros expositivos abaixo, a coluna numérica da esquerda corresponde da menor à maior pontuação (de baixo para cima) e a linha de baixo corresponde às categorias avaliadas nos testes. As colunas cinzas preenchem da menor à maior pontuação daquele grupo em cada uma das categorias.

\section{RESULTADOS}

Para melhor compreensão e detalhamento, os resultados estão apresentados a partir das seis categorias pertencentes ao teste (intensidade, timbre, tempo, duração, altura e apreciação) diante de cada grupo (Gráficos 1, 2, 3 e 4). Atribuiu-se pontuaçáo de 0 a 60 para cada categoria, sendo 20 a menor pontuação obtida (Gráficos 2 e 3$)^{14}$.

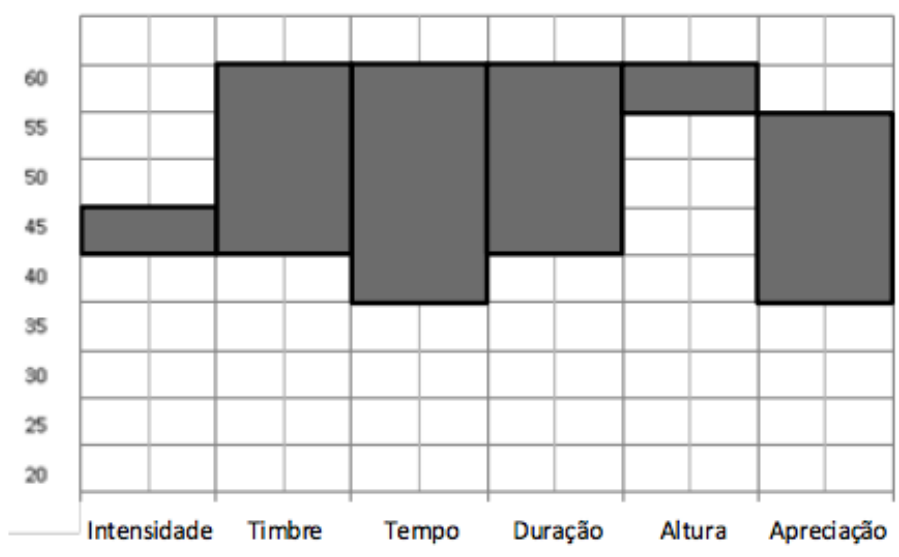

Gráfico 1. Pontuaçáo realizada pelo grupo de 05 e 06 anos (sem deficiência)

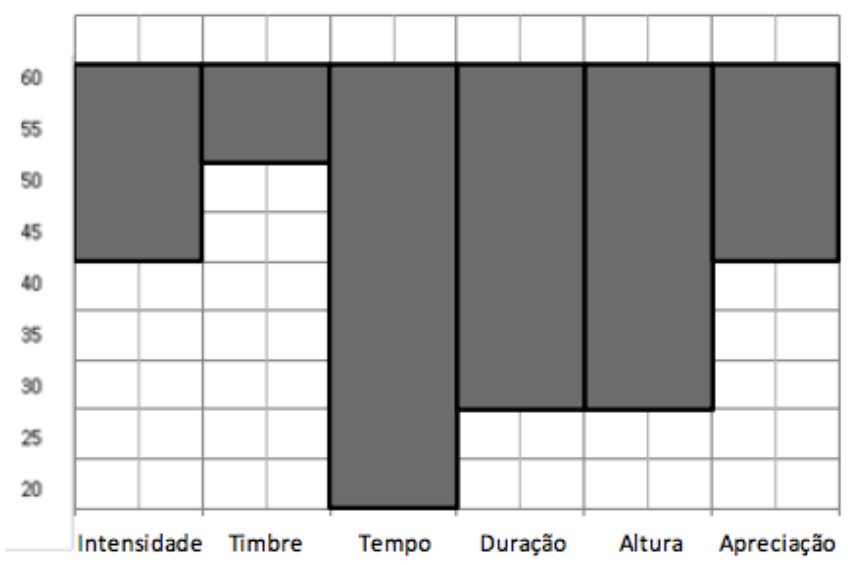

Gráfico 2. Pontuaçáo realizada pelo grupo de 07 a 10 anos 


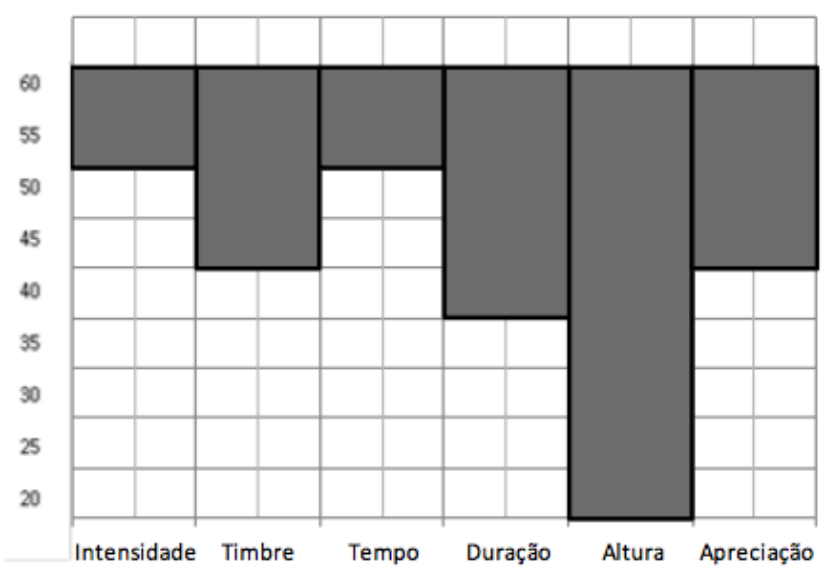

Gráfico 3. Pontuação realizada pelo grupo de 11 a 15 anos (sem deficiência)

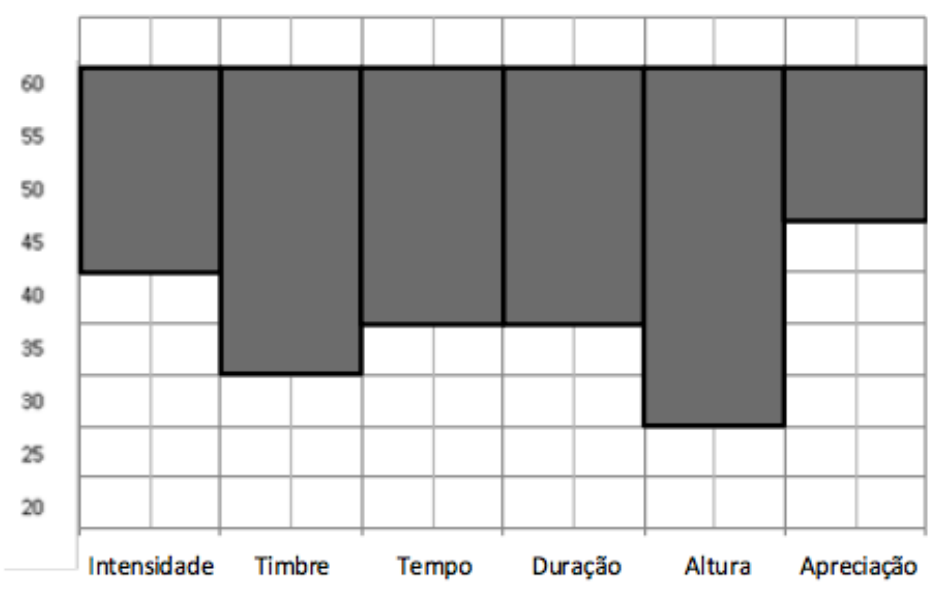

Gráfico 4. Pontuação do grupo de pessoas com deficiência.

A tabela 9 apresenta a pontuaçáo total obtida com a aplicação do teste em todos os grupos.

\begin{tabular}{|c|c|c|c|c|c|}
\hline $\begin{array}{c}\text { Pontuação } \\
\text { Final } \\
\text { VALOR } \\
\text { ABSOLUTO }\end{array}$ & $\begin{array}{c}\text { VALOR EM } \\
\text { PORCENTA- } \\
\text { GEM DE } \\
\text { ACERTOS }\end{array}$ & 5 a 6 anos & $\begin{array}{c}7 \text { a } 10 \\
\text { anos }\end{array}$ & $\begin{array}{c}11 \text { a } 15 \\
\text { anos }\end{array}$ & $\begin{array}{c}\text { Pessoas com } \\
\text { Deficiência }\end{array}$ \\
\hline 360 & 100 & & 1 & 1 & \\
\hline 355 & 98 & & 3 & 5 & 1 \\
\hline 350 & 97 & & & 3 & 1 \\
\hline 345 & 96 & & 1 & 2 & \\
\hline 340 & 95 & & & 1 & 2 \\
\hline 335 & 93 & & & 5 & 2 \\
\hline
\end{tabular}




\begin{tabular}{|l|l|l|l|l|l|}
\hline 330 & 92 & 1 & & & \\
\hline 325 & 90 & & 1 & & 2 \\
\hline 320 & 89 & & 1 & & 1 \\
\hline 310 & 86 & 1 & & & \\
\hline 300 & 83 & & 1 & 1 & 1 \\
\hline 295 & 82 & & 1 & & 1 \\
\hline 290 & 81 & 1 & & & 1 \\
\hline 285 & 79 & & & 1 & \\
\hline 265 & 74 & & 1 & & \\
\hline 260 & 72 & & 1 & & \\
\hline
\end{tabular}

Tabela 9. Quantidade de alunos e pontuaçốes obtidas no teste.

\section{DISCUSSÃO}

Os resultados, embora preliminares, mostram que o grupo que apresentou maior variação de pontuação foi de 07 a 10 anos (maior do que $72 \%$ até $100 \%$ de acertos). Isso provavelmente tenha ocorrido pela variedade da idade: uma criança de 07 anos pode diferir sensivelmente - em termos de desenvolvimento - de uma outra criança de 10 anos, mesmo estando dentro da mesma categoria de desenvolvimento proposta por Wallon. Já o grupo que obteve a menor variação foi o de 05 e 06 anos (desde $82 \%$ até $92 \%$ de acertos). Devido à proximidade etária, náo diferem tanto no desenvolvimento como no grupo de 07 a 10 anos, por isso as notas menos variantes.

No entanto, o grupo de 05 e 06 anos, mesmo sendo o que obteve maior pontuação nas categorias, individualmente, foi o único que não atingiu a pontuação de 60 na categoria apreciação. Isso pode ter ocorrido, pois essa questão (apreciação musical) depende não somente de conteúdos oferecidos em aula, mas também, do contexto cultural do aluno, visto que visa reconhecer estilos musicais diferentes, e nessa idade, poucas crianças possuem uma vivência musical ampla.

Já as menores pontuaçóes foram na categoria tempo, no grupo de crianças de 07 a 10 anos (20 pontos) e na categoria altura, no grupo de adolescentes de 11 a 15 anos (20 pontos). Em relação ao tempo, é compreensível uma nota mais baixa para as idades de 07 a 10 anos, visto que pulsação e 
andamento são conceitos difíceis de serem compreendidos, devido à subjetividade.

No caso da pontuação mais baixa (em altura) entre os adolescentes, não encontramos uma justificativa coerente uma vez que, nessa idade, quem é musicalizado, já deveria ter esses conceitos absorvidos. O que pode ter ocorrido é que, apesar de adolescentes, esse grupo em especial faz aulas de música há pouco tempo (somente seis meses). Sendo assim, talvez ainda estejam num processo de aprendizagem desse conteúdo.

Em relaçáo à pontuaçáo final, podemos destacar que somente duas pessoas chegaram ao máximo (360 pontos $=$ $100 \%$ de acerto), uma no grupo de 07 a 10 anos e outra no grupo de 11 a 15 anos. A menor pontuação foi de um aluno pertencente ao grupo de 07 a 11 anos $(260$ pontos $=72 \%$ de acertos) e a nota mais frequente foi de 355 pontos ( $98 \%$ de acertos), nove pessoas no total, sendo cinco do grupo de 11 a 15 anos, três do grupo de 07 a 10 anos e um do grupo de pessoas com deficiência.

Portanto, percebe-se que na medida em que a faixa etária aumentou, os acertos aumentaram, sendo assim, na faixa de 11 a 15 anos mais alunos atingiram notas maiores. O grupo com deficiência mostrou desempenho similar ao das pessoas sem deficiências, indicando que o procedimento pode ser usado com esse tipo de público também.

O estudo piloto mostrou que todos os grupos conseguiram realizar plenamente o teste e tiveram pontuações semelhantes, o que demonstra que o teste é aplicável em pessoas com e sem deficiência, desde que elas sejam musicalizadas. Pode-se perceber também que o teste possui um nível de exigência razoável, visto que das 45 pessoas (todas musicalizadas), somente duas obtiveram a pontuação máxima. Por outro lado, o teste não é difícil a ponto de não poder ser concluído, pois nenhuma das pessoas obteve nota zero ou muito baixa.

A eficácia do teste, deve-se ao fato de ter sido alicerçado sobre conceitos bem definidos, levando em consideração a maturidade mental, de memória e da linguagem pertencente a cada grupo etário. Por isso, o uso de figuras para crianças de 05 e 06 anos e de atividades puramente escritas para os adolescentes (LURIA, 1992; FONSECA, 2008; LAMPREIA, 2008). Igualmente importantes, foram as adaptaçóes para aqueles não alfabetizados ou com deficiências mais severas, 
pois elas possibilitaram a resposta do teste, sem que esse fosse alterado em relaçáo à sua essência. Isso nos mostra que com pesquisa e um bom embasamento teórico, pode-se atingir a todos, independentemente se possuem ou não deficiências.

O teste foi baseado no desenvolvimento neurológico considerado "normal", pois seria muito difícil validar um teste alicerçado nos padróes do desenvolvimento de uma pessoa com TEA, pois cada quadro difere muito um do outro. Há autistas com cinco anos que se comunicam por meio da fala e outros que não verbalizam. Nessa idade, alguns já desenvolveram habilidades surpreendentes e outros ainda possuem grandes defasagens cognitivas (KLIN, 2006). O comportamento autista pode diferir sensivelmente mesmo em idades próximas e, por isso, não teria um padrão a se seguir para a elaboração de um teste de confiança.

O estudo piloto foi, portanto, fundamental para garantir a viabilidade da pesquisa proposta para estudar a aplicabilidade e a eficácia da avaliaçáo em pessoas com habilidades cognitivas diferenciadas, comparadas ao esperado num padrão considerado normal.

\section{CONCLUSÃO}

Com base no estudo piloto, podemos concluir que:

1. Em relação à duração, o teste pode ser aplicado em uma hora, sendo viável do ponto de vista pedagógico;

2. Quanto à atenção e tolerância, os adolescentes sem deficiência (de 11 a 15 anos) tiveram dificuldade em manter a disciplina em sala, provavelmente, devido à quantidade de repetiçôes realizadas (três vezes em cada exercício). Na pesquisa a ser realizada em pessoas com autismo, o teste será realizado individualmente, portanto a questão da indisciplina não será um fator impeditivo;

3. O enunciado foi compreendido plenamente por todos os alunos, com e sem deficiência;

4. No que tange à gravação dos estímulos para a avaliação das sequências sonoro-musicais, notou-se que é necessário trocar alguns sons das questóes 3 e 4 (timbre) por serem fáceis (óbvias) demais. Ou seja, é possível exigir mais dessas questôes. Além disso, será necessário trocar a faixa 2 da ques- 
tão 2 (intensidade), pois muitos alunos confundiram o trecho musical forte com piano, indicando dubiedade nesse exemplo auditivo;

5. As adaptações foram fundamentais para a realização do teste de alunos náo alfabetizados e se mostraram eficazes e adequadas;

6. Fichas e figuras: todos os alunos puderam reconhecer as figuras e compreenderam a utilização das fichas;

7. Gabarito de pontos: o gabarito idealizado se mostrou plenamente eficiente.

Portanto, o teste batizado de Avaliação Auditiva de Sequências Sonoro-Musicais (AASSM), mostrou-se adequado e eficaz ao que se propóe, necessitando somente de algumas adequações em algumas faixas dos CDs.

\section{BIBLIOGRAFIA}

AMERICAN PSYCHIATRIC ASSOCIATION (APA). Diagnostic and statistic manual of mental disorders. 4th ed. Washington, DC: APA, 1994.

Autism spectrum disorder. Washington: APA, 2013. Disponível em: <http://www.dsm5.org/Documents/Autism $\% 20$ Spectrum $\% 20$ Disorder $\% 20$ Fact $\% 20$ Sheet.pdf> Acesso em 18 Out. 2013.

AMERICAN SPEECH LANGUAGE HEARING ASSOCIATION (ASHA). Central auditory processing: current status of research and implications for clinical practice. Am J. Audiology, 1996.

BARROS, Marisa. A Música como mediadora no desenvolvimento cognitivo em crianças com perturbaçóes Autísticas: Intervenção junto de uma aluna com perturbações Autísticas. 137p. Dissertação (Mestrado em Necessidades Educativas Especiais, no domínio Cognitivo). Escola Superior de Educação João de Deus. Portugal, 2010.

BEKINSCHTEIN P et al. BDNF is essential to promote persistence of long-term memory storage. PNAS, v. 105, n. 7, p. 2711-16, 2008. 
BONALIDI, Laís. et al. Bases anatômicas da audição e do equilíbrio. São Paulo: Santos, 2004.

DIAS, Karin. Processamento auditivo em individuos com Sindrome de Asperger. 386 p. Tese (Doutorado em ciências). Universidade Federal de São Paulo - Escola Paulista de Medicina. São Paulo, 2005.

FILHO, Irineu. et al. As compreensōes do humano para Skinner, Piaget, Vygotski e Wallon: pequena introdução às teorias e suas implicaçōes na escola. Psicologia da Educação, São Paulo, v. 29, p. 27-55, 2009.

FONSECA, Vitor. Cognição, neuropsicologia e aprendizagem: abordagem neuropsicológica e psicopedagógica. Rio de Janeiro: Vozes, 2007.

Desenvolvimento psicomotricidade e aprendizagem. Porto Alegre: Artmed, 2008.

- Observação psicomotora: significação psiconeurológica dos fatores psicomotores. $2^{\mathrm{a}} \mathrm{ed}$. Rio de Janeiro: Wak, 2012.

HARGREAVES, D.; ZIMMERMAN, M. Teorias do desenvolvimento da aprendizagem musical. In: ILARI, B. (Org.). Em busca da mente musical: ensaios sobre os processos cognitivos em música - da percepção à produção. Curitiba: Ed. UFPR, 2006, p. 231-269.

KAFIES. E. et al. Pacientes com deficiência intelectual e espectro autístico e o fazer musical. In: SIMPÓSIO DE COGNIÇÃO E ARTES, IV. Rio de Janeiro, 2008. UFRJ, Maio 2008, p. $1-4$.

KLIN, Ami. Autismo e Síndrome de Asperger: uma visão geral. Revista Brasileira de Psiquiatria. Sáo Paulo, v. 28 sup.1, p. 23-34, 2006.

LAI. Grace. et al. Neural systems for speech and song in autism. Brain: a journal of neurology. v. 135, p. 961-975, 2012.

LAMPREIA, Carolina. O processo de desenvolvimento rumo ao símbolo: uma perspectiva pragmática. Arquivos Brasileiros de Psicologia, Rio de Janeiro, v. 60, n. 2, p. 54-57, 2008. 
LOURO, Viviane. Fundamentos da aprendizagem musical da pessoa com deficiência. São Paulo: SOM, 2012.

LURIA, Alexander. A construção da Mente. Trad. Marcelo Brandão Cipolla. São Paulo: Ícone, 1992.

MATEIRO, Teresa et al. Pedagogias em educação musical. Curitiba: Ibpex, 2011.

MENDONÇA, J. LEMOS, S. Relação entre prática musical, processamento auditivo e apreciaçáo musical em crianças de 5 anos. Revista da $A B E M$, v. 23, p.58-66, 2010.

MOTTRON, L. Local and global processing of music in high-functioning persons with autism: beyond central coherence? Journal Child Psychology and Psychiatry. v. 41, n. 8, p. 1057-1062, 2000.

PACHECO, Caroline. Habilidades musicais e consciência fonológica: um estudo correlacional com crianças de 4 e 5 anos de Curitiba. 172p. Dissertação (Mestrado em Música). Universidade Federal do Paraná. Curitiba, 2009.

PADILHA, Marisa. A musicoterapia no tratamento de crianças com Perturbação no Espectro do Autismo. 100 p. Dissertação (Mestrado em Medicina). Universidade da Beira Interior, Faculdade de Ciências da Saúde. Covilhã, 2008.

PEREIRA, Liliane. et al. Testes auditivos comportamentais para avaliação do processamento auditivo central. São Paulo: Pro-Fono, 2011.

. et al. Processamento auditivo: uma abordagem de associação entre a audição e a linguagem. São Paulo: Manole, 2002.

SILVA, Alexandre. Tradução para o português brasileiro e validação da escala Individualized Music Therapy Assessment Profile (IMTAP) para uso no Brasil. Dissertaçáo (Mestrado em saúde da criança e do adolescente). 330 p. Universidade Federal do Rio Grande do Sul, Faculdade de medicina. Porto Alegre, 2012.

SLOBODA, J. A. A mente musical: a psicologia cognitiva da música. Londrina: Eduel, 2008. 
WALlON, H. A evolução psicológica da criança. São Paulo: Martins Fontes, 2007.

WIGRAM, T. GOLD, C. Music therapy in the assessment and treatment of autistic spectrum disorder: clinical application and research evidence. Faculty of Humanities, Institut of Music and Music Therapy, Aalborg University, Aalborg, 2006.

WECHSLER, David. WISC III: Escala de Inteligência Wechsler para crianças: manual David Wechsler, 3a edição; Adaptação e padronização de uma amostra brasileira. 1 . ed.; Vera Lúcia Marques de Figueiredo. São Paulo: Casa do Psicólogo, 2002. 